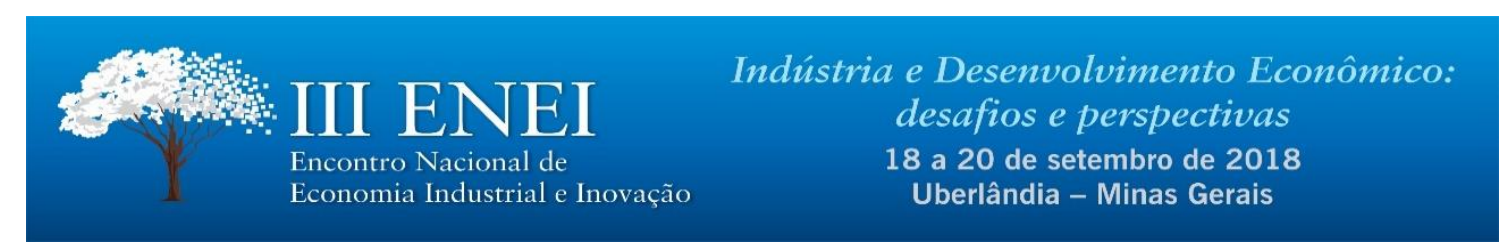

\title{
PARTICIPAÇÃO DE FIRMAS ARGENTINAS EM CADEIAS GLOBAIS DE VALOR: ABORDAGEM EXPLORATÓRIA BASEADA EM MICRODADOS
}

\author{
Mario Augusto Gouvêa de Almeida (Doutorando UFSC - E-mail: mmarioaga@gmail.com) \\ Hoyêdo Nunes Lins (Professor UFSC - E-mail: hoyedo.lins@ufsc.br) \\ Eva Yamila da Silva Catela (Professor UFSC - E-mail: evadasilvacatela@ gmail.com)
}

\begin{abstract}
Resumo: O debate sobre cadeias globais de valor (CGV) ganhou terreno nas últimas décadas, sobretudo com respeito às possibilidades dos países cujas empresas adentram a órbita daquelas estruturas. Temas como divisão internacional do trabalho, ascensão industrial e dinamismo inovador pontilham a discussão, que no fundo evoca a problemática mais geral do desenvolvimento. Inspirado em tal debate, o artigo focaliza de modo exploratório a inserção de firmas industriais argentinas em CGV, utilizando microdados da Encuesta Nacional de Dinámica de Empleo $e$ Innovación (ENDEI), realizada em nível ministerial no país vizinho. O texto inicialmente discute as relações envolvendo $\mathrm{CGV}$, estágios produtivos dos países implicados e o problema da inovação, e posteriormente lança um olhar sobre a indústria argentina conforme permitido pela referida base de dados, colocando ênfase em questões destacadas na literatura.
\end{abstract}

Palavras-chave: cadeias globais de valor; empresas argentinas; indústria

\begin{abstract}
The debate on global value chains (GVC) has gained momentum in recent decades, specially with respect to the possibilities of the countries whose firms enter the orbit of those structures. Issues such as international division of labour, industrial upgrading and innovative dynamism punctuate the debate, which in essence evokes the more general question of development. Inspired by this discussion, this article consider, in a exploratory way, the insertion of Argentine industrial firms in GVC, using microdata from the Encuesta Nacional de Dinámica de Empleo e Innovación (ENDEI), held at the ministerial level in the neighbouring country. The text initially discusses the relations involving GVC, productive stages of the participating countries and the problem of innovation, and later takes a look at the Argentine manufacturing sector as allowed by the data base, placing emphasis on issues highlighted in the literature.
\end{abstract}

Keywords: global value chains; Argentine companies; manufacturing

JEL Classification: F02, F60

\section{Área de Submissão: 2.2 Comércio internacional e cadeias de valor}

\section{Introdução}

A fragmentação internacional dos processos produtivos e a presença de cadeias globais de valor (CGV) ganharam terreno nas últimas décadas, afetando a divisão internacional da produção e do trabalho. O vinculado processo de reorganização da produção e do comércio, sobressaindo a emergência de redes globais ou regionais, reposicionou vários países em desenvolvimento no cenário internacional, como manifestado em crescente participação no comércio nessa escala. A incidência de produtos intermediários nas transações revelou-se crescente, atingindo patamar de quase $60 \%$ do total, o que autoriza considerar constituírem as importações um importante aspecto das redes de produção: assim como no tocante às exportações, o papel das importações na geração de empregos e no crescimento econômico mostra-se essencial. Com efeito, se em 1990 o conteúdo das importações no valor adicionado das exportações era de 20\%, em 2010 o nível exibido 
alcançara $40 \%$, girando em torno de $60 \%$ a expectativa para 2030 . Outro importante aspecto é que os serviços relacionados ao comércio ganharam mais realce, comparativamente à manufatura, cuja fatia no valor do comércio é declinante (LAMY, 2013).

Favorecendo a inserção de países em desenvolvimento em amplas estruturas de produção e comercialização, o referido contexto não deixou de registrar implicações para tais economias. Para algumas, a participação em CGV contribuiu para o crescimento do produto e das exportações, representando ganhos de curto prazo. Para outras, o envolvimento proporcionou mudanças na composição das estruturas produtivas rumo a estágios produtivos mais elevados, rimando com mudança estrutural e ganhos de longo prazo. Daí que tentar compreender como as empresas de um país participam de CGV, em associação com o estágio produtivo da referida economia nacional, consiste em procedimento relevante no campo de interesse do desenvolvimento econômico, permitindo evocar questões como armadilha da renda média, mudança estrutural e crescimento de longo prazo.

O objetivo deste trabalho é analisar a inserção das firmas industriais argentinas em CGV. Sua base são os microdados da pesquisa Encuesta Nacional de Dinámica de Empleo e Innovación $(\text { ENDEI })^{1}$, que informa sobre o período entre 2010 e 2012 para uma amostra - estratificada por setor e por tamanho - de 3.691 firmas da indústria de transformação daquele país, integrantes de um universo de 15.368 firmas. Na concebida estrutura de texto, a seção seguinte contém uma revisão bibliográfica sobre as relações entre o envolvimento de países em CGV, estágios produtivos e inovação. Na terceira seção, apresentam-se as hipóteses do estudo e as estatísticas descritivas ligadas aos microdados, e desenvolve-se a abordagem econométrica utilizada. A isso seguem-se os comentários finais.

\section{Cadeias globais de valor, estágios produtivos e inovação}

A referência às cadeias globais de valor $(\mathrm{CGV})$ marca diversas abordagens sobre o comércio ligado à distribuição internacional de atividades produtivas. Nessa literatura, a produção (bens intermediários e finais) aparece fragmentada em diferentes espaços (países, regiões) e a localização das diversas atividades mostra-se condicionada pelas vantagens comparativas "caleidoscópicas" encontradas. Este termo foi utilizado por Bhagwati e Dehejia (1994) para referir às vantagens relacionadas a cada etapa do processo produtivo, em contraste com aquelas associadas à produção de bens finais, explorada na teorização tradicional.

Com efeito, para Timmer et al (2013), as CGV representariam um complemento à ideia inicial de comércio internacional e vantagens comparativas, presente na obra de Ricardo (1996). Nesse sentido, os autores assinalam que a fragmentação da produção em diversos locais expande as oportunidades e amplia ainda mais os benefícios para os envolvidos no comércio. Na média, existiria um ganho de bem estar em todas as economias participantes, ainda que - segundo a ressalva indicada - isso não necessariamente ocorra para todos os implicados (trabalhadores, empresários) no país. A razão é que as várias etapas dos processos produtivos representam diferentes níveis de agregação de valor, e sua separação permite aos países se concentrarem na captura de valor adicionado (VA) em fases específicas.

\subsection{Cadeias globais de valor e possibilidades dos países}

Segundo Baldwin (2011), nessa forma de organizar a produção crescem as opções de desenvolvimento inclusive para as nações pobres. Com efeito, participar de CGV acena com presença em mercados praticamente inacessíveis em outras circunstâncias, sem que, para tanto, sejam necessários investimentos por longos períodos em setores ou segmentos que podem, como se observou numerosas vezes, sequer dar resultados condizentes. A propósito das aludidas opções, cabe também ressaltar o problema relativo à dificuldade de transferir conhecimento, conforme

\footnotetext{
${ }^{1}$ Publicada em 2015, trata-se de uma pesquisa conjunta dos Ministérios de Ciência, Tecnologia e Inovação Produtiva, o de Trabalho, Emprego e Seguridade Social da Argentina, junto ao Banco Interamericano de Desenvolvimento (BID).
} 
abordado no Atlas de Complexidade Econômica ${ }^{2}$, que trata dos obstáculos que se interpõem ao aprendizado do conhecimento tácito, já que nem todas as atividades são transferíveis. Timmer et al (2013) assinalam que, para países pouco industrializados, a inserção em CGV constitui alternativa mais rápida nesse sentido, comparativamente à antiga estratégia de substituição de importações, que mirava na internalização da produção das mercadorias consumidas localmente.

Se fragmentar as atividades representa condições diferenciadas para inserção nos processos produtivos, é importante indagar sobre as características dessa diversidade. Baldwin (2012) indica que as etapas geradoras de maior VA referem-se aos estágios pré e pós-fabricação, formados basicamente por serviços - incluindo concepção, design, pesquisa e desenvolvimento (P\&D), vendas, marketing e serviços pós-venda -, cujas diferentes capacidades quanto à criação daquele valor são apontadas na chamada "curva sorriso" (smile curve), apresentada pelo referido autor. O maior VA dessas etapas reflete as habilidades específicas necessárias à execução das atividades geradoras de produtos diferenciados. Ressalte-se, contudo, que as atividades de serviços são, elas próprias, heterogêneas, o que quer dizer diferenciação na capacidade de criar VA mesmo no interior desse grupo de atividades.

A figura 1 mostra a adaptação efetuada por Corrêa et al (2017) - à direita na figura - na "curva sorriso" de Baldwin (2012) - à esquerda na figura - , indicando, além das diferentes capacidades de geração de valor das atividades envolvidas na cadeia, as etapas referentes ao fornecimento de matérias primas e à produção de peças e componentes. A primeira etapa registra baixa capacidade de criação de VA, tanto quanto as atividades de montagem/processamento do produto final; a segunda abriga alto potencial de VA, por conta do incrustado conteúdo tecnológico e do conhecimento associado. É também importante destacar, sobre a comparação entre essas configurações da "curva sorriso", que em Baldwin (2012) há uma visão mais geral da atividade econômica com respeito ao VA gerado em cada segmento. Nota-se reflexo de perspectivas analíticas assimiláveis ao que se percebia entre os anos 1970 e o início dos anos 2000, quando se destacava tendência de perda de espaço das atividades manufatureiras para os serviços. Assim, a correspondente curva não considera o fornecimento de insumos e matérias primas, uma esfera de atividades de grande importância quando se trata de observar a geração de VA em países como Argentina ou Brasil. A versão adaptada, em Corrêa et al (2017), inclui essa questão ao levar em conta o fornecimento de matérias primas, o processamento e a montagem final de produtos como atividades de menor VA na cadeia. Essas atividades vêm sendo deslocadas para países em desenvolvimento ao longo do tempo, um processo que tem no Brasil, no México e na Argentina ilustrações latino-americanas eloquentes.

A abordagem das CGV, focando os desdobramentos da fragmentação geográfica das redes de produção, põe ênfase em dois importantes aspectos: i) a governança dos atores da cadeia, incluindo a maneira como as firmas líderes controlam outras empresas; ii) as políticas governamentais dos países em desenvolvimento voltadas ao upgrading de suas posições na economia global, objetivando sobretudo melhorá-las. Nesse sentido, adota-se perspectiva tanto topdown - ao incorporar na análise o problema da governança - quanto bottom-up - ao analisar as estratégias voltadas ao upgrading (GEREFFI; STURGEON, 2013; GEREFFI, 2001).

Sobre a governança dos integrantes da cadeia, é a posição de uma empresa na respectiva rede de vínculos que define os benefícios extraídos da participação. As firmas com posição central logram gerar e reter competências e recursos que dificilmente podem ser replicadas pelos competidores, o que permite coordenar atividades e funções diversas rumo a um mesmo objetivo. Quer dizer, a captura do valor depende das posições diferenciadas das firmas na estrutura de produção e distribuição das CGV. Gereffi, Humphrey e Sturgeon (2005) identificam diferentes modelos de governança nessas estruturas, considerando notadamente a complexidade das transações dentro da cadeia, o grau de codificação potencial do conhecimento gerado e movimentado no seu

\footnotetext{
2 Hausmann et al (2011), em parceria entre o Media Lab do MIT e a Kennedy School de Harvard (https://atlas.media.mit.edu/en/). Com base na análise da pauta exportadora de um determinado país, os autores medem de forma indireta a sofisticação tecnológica do correspondente tecido produtivo ou a sua "complexidade econômica".
} 
interior e a capacitação dos fornecedores. Num extremo do leque de possibilidades, figura a governança por meio do mercado, mais provável quando as especificações dos produtos são simples e codificáveis (o que dificulta a acumulação de ativos específicos por algum participante) e quando não há requisitos muito sofisticados quanto à capacitação dos fornecedores. No outro extremo, em situações em que, por exemplo, as especificações de produto não podem ser codificadas, os produtos são complexos e é muito custoso (e/ou arriscado) capacitar fornecedores, mostra-se grande a probabilidade da cadeia se apresentar de modo hierarquizado, com integração vertical.

Figura 1 - A curva sorriso: versão original (A) e versão adaptada (B)

A

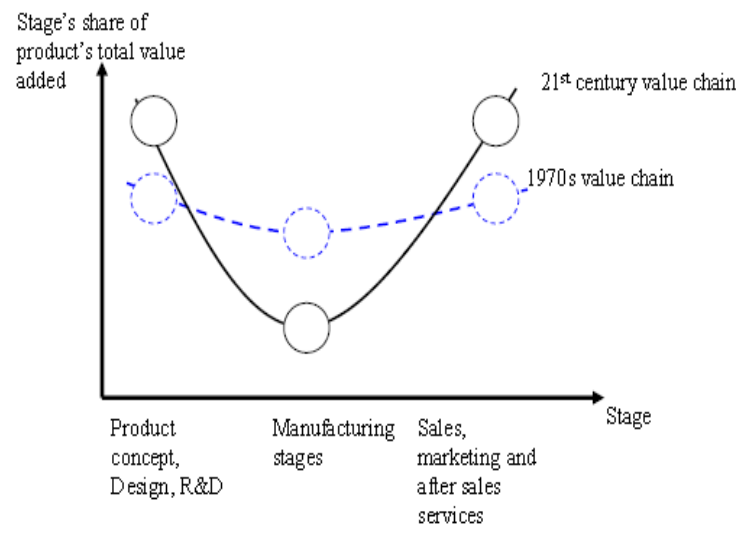

B

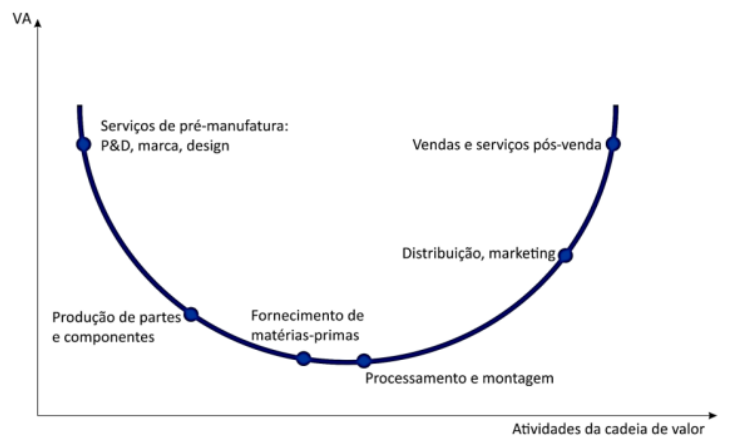

Fonte: Baldwin (2012) e Corrêa et al (2017)

Apesar da variedade de estruturas das CGV, esse tipo de configuração ampliou as chances de participação de diferentes atores nos processos produtivos e intensificou o comércio internacional de bens intermediários, tanto entre empresas como intrafirma. Ao mesmo tempo, cresceu a competição internacional, nas diferentes etapas produtivas, e ocorreu alteração significativa na divisão internacional do trabalho (PINTO et al, 2017). Tendo como pano de fundo uma marcada diferenciação na captura de valor adicionado entre as atividades que compõem os processos produtivos, os países em desenvolvimento aparecem atuando cada vez mais como fornecedores de matérias primas ou em atividades de processamento e montagem de produtos finais. Os países desenvolvidos ampliaram a sua participação em atividades de maior VA, como produção de peças e componentes de alta tecnologia, ou, mais especificamente, passaram a se concentrar em segmentos de serviços intensivos em conhecimento, como em criação do produto, design e P\&D (MEMEDOVIC; IAPADRE, 2009). Tal clivagem remete ao debate, no que concerne aos países em desenvolvimento, sobre as políticas governamentais voltadas ao upgrading na participação em CGV.

Conforme ressaltado por Pinto et al (2017), o referido debate registra como uma questão central o aumento do VA criado domesticamente, entendido como resultado capaz de lubrificar a dinamização das economias nacionais. Cabe sublinhar, nesse sentido, que a participação em redes internacionais de produção representa avanço industrial em diversos países, com reflexos de curto prazo em aumento de exportações, emprego e renda. Em alguns, os ganhos se estendem no longo prazo, pela maior atuação em segmentos geradores de efeitos de transbordamento para outros setores, inclusive de maior sofisticação, aumentando a produtividade e contribuindo para o desenvolvimento nacional (UNCTAD, 2013; MEMEDOVIC; IAPADRE, 2009). Para os países cujos benefícios restringem-se ao curto prazo, a mudança do padrão de especialização da economia pode limitar-se ao setor exportador, com poucos efeitos de encadeamento e com escassa variação da produtividade. Nesses casos, a sofisticação das exportações não se reflete na melhora da estrutura produtiva, podendo inclusive caracterizar um aprisionamento (lock-in) do país em atividades de baixo VA, vinculado à reduzida endogeneização tecnológica e ao limitado dinamismo econômico 
decorrente. Um exemplo clássico refere-se à armadilha da renda média: ao atingirem um nível médio de renda, os países não conseguem avançar para estágios de desenvolvimento superior, o que se verifica quando deixam de competir via preço com economias de baixa renda, em virtude dos seus maiores níveis salariais, e não criam condições para competir com economias mais avançadas, cujos produtos são mais intensivos em conhecimento (EICHENGREEN, 2011).

Portanto, faz sentido considerar que a forma como os países se apropriam das possibilidades geradas pelas $\mathrm{CGV}$ afeta os respectivos processos de desenvolvimento. Falar sobre isso implica levar em conta a problemática do upgrading. O termo foi referido por Milberg e Winkler (2013) como um instrumento para, mediante movimentos ao longo da cadeia objetivando uma maior captura de VA, superar o padrão de especialização ditado pelas vantagens comparativas. Em alguns países, a atuação em cadeias restringe-se ao tipo de atividade desempenhada durante a própria inserção, enquanto em outros se registra uma atuação mais abrangente e representativa de avanços em termos de, alternativamente ou não, maior eficiência nos processos produtivos (upgrading de processo), melhores produtos (upgrading de produto), direcionamento para cadeias de valor mais sofisticadas (upgrading de cadeia) e projeção rumo a atividades implicando maior intensidade de conhecimento (upgrading funcional) ${ }^{3}$.

Esses diferentes tipos de upgrading podem ser indicados na contribuição de Corrêa et al (2017), na adaptação da "curva sorriso" de Baldwin (2012), conforme apresentado na figura 1. No upgrading funcional observa uma migração para atividades mais intensas em conhecimento e, portanto, representa um deslocamento sobre a curva com maior potencial de criação de VA. Nos outros três tipos de upgrading, podem-se observar países que desempenham as mesmas atividades, embora com diferentes capturas de VA, devido à sofisticação no tocante a processo, produto ou cadeia. Ou seja, apesar de desempenharem atividades semelhantes os países não estão na mesma curva e, nestes casos, upgrading se traduz num deslocamento do país para uma curva acima. Notese que os estágios produtivos são aqui definidos com base na predominância de determinados setores nessas economias, que se refletem nas respectivas performances em termos de emprego, produto, exportação e crescimento econômico (UNIDO, 2013).

\subsection{Percursos nos estágios produtivos de cadeias globais de valor}

Com relação à dinâmica pela qual os países se inserem e percorrem os estágios produtivos, Corrêa et al (2017) ressaltam que, nas economias em estágios produtivos iniciais, as estruturas produtivas exibem basicamente manufaturas de baixa intensidade tecnológica e elevada intensidade em mão de obra e/ou recursos naturais (alimentos, têxtil, vestuário). Tais setores têm grande potencial de criação de emprego, embora de baixa qualificação, e sua predominância caracterizaria países que decolam no seu processo de industrialização. Tal padrão de especialização ajuda a aumentar a produtividade e o crescimento do produto (lei Kaldor-Verdoorn ${ }^{4}$ ), mas apresenta limitações quanto à acumulação de capital devido à baixa intensidade tecnológica dos segmentos. $\mathrm{O}$ avanço no estágio produtivo refere-se à maior participação de manufaturas de média e alta intensidade tecnológica, mas ainda com importante presença de níveis mais baixos nesse aspecto. $\mathrm{O}$ êxito do processo induz os países à diversificação para segmentos mais sofisticados e rentáveis, como metais básicos e produtos fabricados de metais, e, posteriormente, na esteira do aprofundamento, rumo às indústrias de equipamentos de transporte e eletrônicos. Embora as indústrias intensivas em tecnologia empreguem menos que as de baixa tecnologia, os empregos gerados são mais qualificados. Assim, além da maior produtividade no próprio segmento, uma articulação significativa com atividades de outros setores (via demanda por insumos e serviços, por

\footnotetext{
${ }^{3}$ Pietrobelli e Rabellotti (2006) e Humphrey e Schmitz (2002) ampliam o estudo em torno dos diferentes tipos de upgrading.

${ }^{4}$ A Lei de Verdoorn, referindo-se à relação entre crescimento da produção e da produtividade, postula que no longo prazo a segunda tende a se expandir proporcionalmente à raiz quadrada da primeira. Ver, por exemplo, Verdoorn (1980).
} 
exemplo) representaria transbordamentos e contribuiria mais fortemente para aumentar a produtividade em termos gerais.

Nos estágios mais avançados figuram países em cujas estruturas produtivas predominam setores intensivos em conhecimento, algo típico das manufaturas de alta intensidade tecnológica máquinas, equipamentos eletrônicos e de transporte -, e também serviços associados a essas atividades, como os financeiros, de transporte e aqueles ligados à TI. Nesse nível, a competitividade baseia-se na busca constante pela maior diferenciação e inovação, mostrando-se tal investida vinculada à fronteira tecnológica existente. A elevada produtividade dessas atividades, associada ao grande potencial de transbordamento incrustado, contribui para uma alta taxa de acumulação de capital nesses países.

Construída com base na ideia de padrões de atuação dos países em $\mathrm{CGV}$, considerando os estágios produtivos, a figura 2 - extraída de Corrêa et al (2017) - apresenta três possíveis patamares de atividades e de possibilidades de trajetória, com expressão nas "curvas sorrisos" de cada um. O eixo horizontal registra os diferentes estágios produtivos dos países, e o vertical diz respeito ao potencial de criação de valor adicionado em cada fase. Segundo os autores, em cada nível os países podem atuar em diversas atividades nas cadeias, com distintos potenciais de criação de VA.

Figura 2 - Inserção dos países nas cadeias em diferentes estágios produtivos

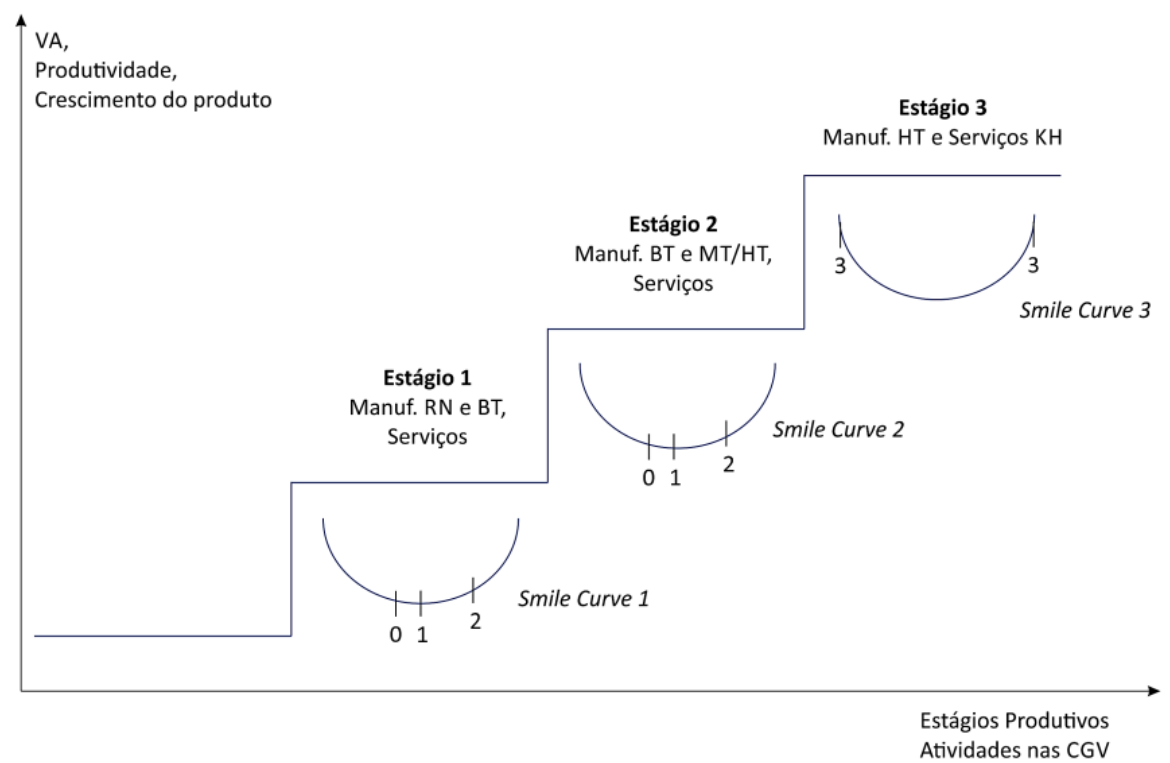

Fonte: Corrêa et al. (2017)

Obs.: Manufatura intensiva em recursos naturais (RN), manufaturas de baixa intensidade tecnológica (BT), de média intensidade tecnológica (MT), de alta intensidade tecnológica (HT) e serviços intensivos em conhecimento (KH). Os números sobre as curvas referem-se à posição dos países nas CGV, quanto aos diferentes estágios produtivos: 0 . Fornecimento de insumos, 1. Atividade de processamento e montagem, 2. Serviços pós-manufaturas, 3. Serviços pré e pós-manufaturas intensivos em conhecimento.

Nos países situados no primeiro estágio, a inserção nas CGV ocorre geralmente em atividades de processamento, em segmentos manufatureiros intensivos em recursos naturais ou trabalho e de baixa intensidade tecnológica. As CGV associadas a esses setores tendem a ser lideradas por compradores (firmas líderes) ${ }^{5}$, que ditam as especificações dos produtos às firmas (sub)contratadas, depois incluindo suas próprias marcas. Nesse estágio produtivo também se observam alguns países com atividades de serviços pós-manufaturas de menor valor adicionado, e ainda países que apresentam baixo nível de industrialização e abundância em recursos naturais,

\footnotetext{
${ }^{5}$ A liderança por compradores refere-se a uma das formas de governança em CGV indicadas em Gereffi (1994); outra forma diz respeito às cadeias lideradas por produtores.
} 
como metais básicos e petróleo, com participação em CGV integralmente ligada ao fornecimento dessas matérias primas. De todo modo, apesar dos escassos encadeamentos propiciados, essa maneira de participar permite auferir os primeiros retornos em termos de emprego, renda e produtividade, podendo representar importante impulso nos respectivos processos de expansão industrial.

No segundo estágio produtivo, os países inserem-se em cadeias de maior sofisticação tecnológica, como as de eletrônicos e equipamentos de transporte. Nessas cadeias, que são lideradas por produtores, a firma líder fornece os insumos necessários (peças e componentes de alta intensidade tecnológica) à montagem dos produtos finais pelas contratadas. Embora sejam setores mais sofisticados tecnologicamente, a participação se dá em etapas intensivas em mão de obra (processamento e montagem). Tal modo de inserção também contribui, ao menos inicialmente, para aumentar o emprego, a renda e a produtividade. A observação permite constatar países em segmentos de serviços também representativos de baixo VA, e países com nível de industrialização um pouco mais alto - com parques produtivos diversificados -, mas que, por apresentarem níveis salariais maiores, não conseguem lograr presença em etapas de processamento, ao mesmo tempo em que suas estruturas tecnológicas não permitem atuação em segmentos mais sofisticados (algo que remete à armadilha da renda média). Assim, por conta da sua abundância em recursos naturais, tais países têm participado das CGV, basicamente, como fornecedores de matéria prima.

O terceiro estágio produtivo caracteriza o padrão de inserção referente aos países desenvolvidos, cuja atuação diz geralmente respeito à "criação" de CGV, já que o processo de fragmentação produtiva derivou dos avanços tecnológicos e estratégias de grandes corporações (firmas líderes) geralmente sediadas nesses países. Tais organismos mantiveram centralizadas suas atividades principais - o core business -, representativas de maior VA, e distribuíram em vários países em desenvolvimento as demais atividades, mormente as mais intensivas em trabalho. Note-se que nesse estágio os países podem atuar em atividades de VA um pouco mais baixo, indicados por outros pontos da mesma curva, principalmente no que concerne às economias nacionais que, mesmo já tendo atingido esse patamar, apresentam nível de renda inferior.

\subsection{A problemática da inovação com vistas ao upgrading em cadeias}

Posteriormente à fase de inserção nas cadeias, que pode ocorrer em qualquer ponto considerado na figura 2, os países podem evoluir também em termos de upgrading de produto e processo e/ou upgrading de cadeia e funcional. Nos dois primeiros, os ganhos no curto prazo se traduzem restritamente em aumento das exportações e de produto, não significando uma mudança da posição relativa do país relativa na cadeia. Nas outras duas formas, o efeito de transbordamento decorrente do processo de endogeneização tecnológica tende a se mostrar elevado, podendo contribuir para a evolução da estrutura produtiva do país, conforme Corrêa et al (2017).

Como se nota, no contexto das CGV o processo de inovação tecnológica nos países em desenvolvimento relaciona-se diretamente seja às posições hierárquicas das suas firmas no interior das cadeias, seja às condições estruturais locais para o desenvolvimento e o avanço de atividades mais sofisticadas. O segundo aspecto remete à discussão em torno dos sistemas nacionais de inovação $(\mathrm{SNI})$, com respeito às repercussões junto às firmas nacionais, mirando-se o problema da ampliação e intensificação dos processos de inovação, com geração de propriedade intelectual, marcas comerciais e patentes, entre outras coisas (PINTO et al, 2017). Esses fatores determinarão se o país em desenvolvimento conseguirá inserir-se na CGV e obter algum grau de upgrading até determinado limite, sem conseguir ultrapassar a barreira da renda média, ou se conseguirá ultrapassar este limite, criando as condições para que o upgrading gere um mecanismo de desenvolvimento capitalista de longo prazo.

Tais questões remetem à problemática da inovação. Sobre o assunto cabe referir, por exemplo, à posição de Viotti e Macedo (2003) - baseada em considerações de natureza sistêmica sobre inovação e impregnada de visão de política industrial de índole evolucionária ou neoschumpeteriana - segundo a qual as empresas não inovam isoladamente. Ao contrário, a 
inovação tem lugar no âmbito de redes de relações (diretas ou indiretas) com outras empresas, além do benefício outorgado por infraestrutura, pesquisa pública e privada, instituições de ensino e pesquisa e outras que, somadas a um sistema normativo, formam o SNI. Estudando o assunto, Pietrobelli e Rabellotti (2006) mostram como os SNI dos países em desenvolvimento podem operar como instrumentos de acesso ao conhecimento e ao aprendizado e como apoio à inovação para as firmas nacionais.

De fato, desde o início dos anos 1990, no bojo de uma crescente literatura sobre sistemas de inovação $^{6}$, destaca-se em numerosas pesquisas ${ }^{7}$ a natureza interconectada e interdependente da inovação, assinalando que o conhecimento necessário para tal processo é cada vez mais multidisciplinar e existente também fora da empresa. Nesse contexto, Chesbrough (2003) propõe a utilização do termo "inovação aberta" para referir à inclusão da inovação como variável estratégica no modelo de negócios, com a função de criar e capturar valor para a empresa. O processo de inovação é entendido como amplamente nutrido por fluxos internos e externos de conhecimento e tecnologia, e, portanto, revela-se dependente da interação da empresa com atores externos. Porém, a eficácia do processo de "inovação aberta" exige que as empresas tenham o que Cohen e Levinthal (1990) denominaram "capacidade de absorção" (CA), definida pela habilidade da firma em reconhecer o valor da informação externa, assimilá-la e aplicá-la para fins comerciais. Tal capacidade mostra-se escorada em conhecimentos oriundos dos departamentos formais de P\&D, do ambiente de produção da firma ou simplesmente dos indivíduos que dela fazem parte.

A referida CA tende a se ampliar quando estão presentes modos de aprendizagem que dizem respeito, de um lado, à maior intensidade de conhecimento tácito (implicando principalmente learning by doing, by using e by interacting), e, de outro, à maior incidência de conhecimento codificado (vinculado ao chamado Science, Technology and Innovation STI - mode), que inclui atividades de P\&D e interações com universidades e centros de pesquisa (JENSEN et al., 2007). Empresas com maiores CA conseguem explorar o conhecimento externo de formas mais eficientes, aumentando seu desempenho inovativo, conforme observado em Escribano et al (2009) em amostra de 2.265 firmas espanholas. Ebers e Maurer (2014) e Murovec e Prodan (2009), de sua parte, constataram empiricamente que empresas com maior CA apresentam maior probabilidade de inovação em produto e processo. Os trabalhos de Laursen e Salter (2014) e de Ince et al. (2016) também detectaram o impacto positivo da CA no processo de inovação.

Como a complexidade que criva a prática da inovação aponta para usos cada vez mais frequentes de modelos de "inovação aberta", e o emprego eficiente desses modelos depende da CA inerente à empresa, cabe indagar sobre as relações entre as fontes externas de informação e também sobre a existência de diferenças importantes entre elas, quando observadas pelo ângulo da firma. A literatura aponta a existência de grandes diferenças nos parceiros envolvidos em cooperação, no sentido indicado. As universidades e os institutos de pesquisa há muito são reconhecidos como importantes fontes de oportunidades tecnológicas, pelo desenvolvimento de ciência básica e aplicada, além do treinamento de mão de obra qualificada para as empresas (KLEVORICK et al., 1995). Hsieh (2017) frisa que a cooperação com universidades subjaz de maneira representativa ao desenvolvimento de inovações em produto, favorecendo uma presença em novos termos no mercado, não poucas vezes com abertura de novos segmentos (BELDERBOS et al, 2004; MENTION, 2011). Ao menos em parte, isso tem a ver com a existência nas universidades de laboratórios de pesquisa especializados, não disponíveis no âmbito das empresas. Empregando cientistas altamente qualificados, tais estruturas desenvolvem conhecimentos teóricos, enquanto as empresas se concentram em conhecimento aplicado (BSTIELER et al., 2015). Mas é a combinação de ambos os tipos de conhecimento que pode propiciar a inovação radical (UM; ASAKAWA, 2015;

\footnotetext{
${ }^{6}$ Conforme originalmente definidos por Nelson (1993) e Lundvall (1992), por exemplo.

${ }^{7}$ Como referências cabe indicar: Carlsson (1997), Edquist (1997, 2005) Chesbrough (2003), Coombs et al. (2003), Malerba (2004, 2005), Tether e Metcalfe (2004), Asheim e Gertler (2005), Powell e Grodal (2005).
} 
WIRSICH et al., 2016), e, portanto, a colaboração universitária sobressai no desenvolvimento de inovações e na contribuição para o upgrading de processo e produto.

Por outro lado, como assinala Hsieh (2017), a colaboração com consultores e institutos de pesquisa privados é mais propensa a favorecer inovações incrementais. Os consultores ajudam as empresas a inovar, mas, em geral, isso não envolve o desenvolvimento de novas tecnologias, e sim por meio de ideias e de tecnologias e conhecimentos intermediários, fruto da observação em várias empresas de diversas indústrias, em diferentes locais. Essas interações permitem aos consultores transferir conhecimento tácito de um contexto para outro, adaptando-o conforme as necessidades de cada empresa, razão pela qual as relações com tais fontes de conhecimentos especializados estariam mais associadas ao upgrading de cadeia e ao upgrading funcional.

\section{A indústria argentina e as cadeias globais de valor}

Com base na revisão da literatura sobre CGV, destacando aspectos ligados às possibilidades dos países, aos percursos produtivos no âmbito das cadeias e, tendo-se em conta as exigências para upgrading, à problemática da inovação, examina-se a inserção em CGV de empresas de um país específico, a Argentina. Inicia-se pela formulação de algumas hipóteses aptas a nortear a observação da participação de economias de renda média em CGV.

\subsection{Hipóteses para orientar a abordagem da inserção de empresas industriais argentinas em CGV e dos correspondentes reflexos}

H1: A inserção de uma economia de média renda em CGV implica manufaturas de baixa intensidade tecnológica (BT), média intensidade tecnológica (MBT/MAT) e alta intensidade tecnológica (AT), além de fornecimento de insumos.

H2: A inserção de uma economia de renda média acontece em etapas intensivas em mão de obra, processamento e montagem, sem a presença de processo de endogeneização tecnológica, sendo forte, assim, a preponderância de provedores externos, o que repercute em perda de valor adicionado (VA) pela economia do país.

H3: Empresas com maior capacidade de absorção (CA) de informação conseguem explorar o conhecimento externo de forma mais eficiente, aumentando o seu desempenho inovativo e sua inserção em CGV.

H4: A colaboração indústria-universidade promove o desenvolvimento de inovações com elevado grau de complexidade, incluindo novos produtos e favorecendo uma participação em CGV escorada em maior desenvolvimento e complexidade em produtos e processos.

\subsection{Fonte dos dados e metodologia}

Objetivando examinar variáveis indicativas da inserção de empresas argentinas em CGV, utilizou-se a base de dados referente à Encuesta Nacional de Dinámica de Empleo e Innovación (ENDEI), desenvolvida pelo Ministerio de Trabajo, Empleo y Seguridad Social (MTEySS) em parceria com o Ministerio de Ciencia, Tecnología e Innovación Productiva daquele país. A pesquisa que originou essa base cobriu 3.691 empresas com 10 ou mais trabalhadores pertencentes à indústria de transformação, integrantes de um universo de pouco menos de 18.000 empresas. A amostra representa $29 \%$ da indústria de transformação argentina, que concentra $88 \%$ do emprego formal industrial registrado (ENDEI, 2015). A pesquisa abrangeu o período 2010-2012.

Assume-se que as empresas mais fortemente inseridas em CGV são as que conseguem atingir mercados globais com seus produtos. Daí ter-se construído uma variável binária (Y) pela qual as empresas declaram exportar (1) ou não exportar (0), rumo a qualquer mercado externo e considerando-se os seguintes recortes: Mercosul e América Latina; América do Norte; Europa; Ásia, África e Oceania. Dada a natureza da variável desfecho, o modelo de estudo escolhido foi o 
Probit $^{8}$. Entende-se também que existe um vetor $X$ de variáveis explicativas que alteram a probabilidade de $Y$, e, assim, considera-se que o modelo possui a seguinte forma:

$$
\operatorname{Prob}\left(Y_{\mathrm{i}}=1 \mid X_{i}\right)=\Phi\left(X^{T} \beta\right)
$$

em que Prob denota a probabilidade e $\Phi$ é a função de distribuição acumulada (FDP) de uma distribuição normal padrão. Os parâmetros $\beta$ são estimados por maximo verossimilhança.

Dessa forma, com base nas características da empresa $i$, chega-se a um valor para $Y_{i}$ que identifica o tipo de vínculo com maior probabilidade de se mostrar presente em tal empresa. Na abordagem, o foco recai na significância, e o sinal dos parâmetros $\beta$ indica quais variáveis têm relação com o tipo de vínculo estabelecido, além de apontar se tal relação é positiva ou negativa.

Todas as variáveis independentes foram selecionadas junto aos microdados da referida base de dados. Para uma melhor estimação do modelo, utilizam-se como controle as variáveis binárias relacionadas ao tamanho da empresa: pequena, média ou grande [tam_peq tam_med tam_gra]. A seguir apresentam-se as variáveis e os fundamentos conceituais/analíticos cuja observação é pretendida:

- [AT MAT BT MBT]: variáveis dicotômicas indicando se a empresa pertence ao grupo de alto, médio alto, baixo ou médio baixo nível tecnológico dos setores industriais, conforme a tabela 1 , que lista os 27. Espera-se que, quanto maior o nível tecnológico, melhor é a inserção da economia em CGV.

- [importa]: variável dicotômica que considera provedores de insumos fora do país, permitindo uma dupla interpretação: a inserção em CGV é maior quanto mais volumosa é a importação de insumos; com importações, a economia deixa de internalizar parcela significativa do VA, e participa dos estágios iniciais da trajetória produtiva. Essa variável também é avaliada conforme o seu alcance (Mercosul e América Latina; América do Norte; Europa; Ásia, África e Oceania).

- [inova]: variável dicotômica que indica se a firma praticou alguma inovação no período, seja de produto, processo ou organizacional. É uma proxy para inovação que leva a upgrading, sendo esperada uma relação positiva com as exportações.

- [result_merc]: variável dicotômica que indica se a inovação realizada resultou em ingresso em novos mercados. É uma proxy para inovação que propicia a entrada em novos mercados e em CGV, esperando-se uma relação positiva com as exportações.

- [uni_inst]: variável dicotômica que indica se a empresa estabeleceu vínculos de colaboração com universidades e/ou instituições públicas de C\&T para desenvolver inovações. Conforme sugerido na literatura, essa variável apontaria a inserção da empresa em CGV por meio de inovação radical, relacionando-se com upgrading de cadeia e funcional.

- [consultores]: variável dicotômica que capta a criação de vínculos de colaboração da empresa com consultores; indicaria a participação em CGV mediante inovações incrementais, relacionando-se com upgrading de produto e de processo.

- [fontes_ext]: variável de contagem que assinala o número de fontes externas utilizadas pela firma no período, entre as seguintes alternativas: firmas do mesmo grupo de controle; provedores e/ou clientes; competidores; consultores; universidades públicas e/ou privadas; instituições públicas de C\&T; internet e redes de informação; câmaras empresariais; feiras, exposições, conferências e congressos; publicações técnicas, catálogos e revistas do setor. Quanto mais numerosas as fontes de informação utilizadas, mais aberta é a empresa e maior a sua capacidade de absorção de conhecimento e de alcance de upgrading.

- [ln_inv]: média dos anos 2010 a 2012 do logaritmo dos gastos com atividades de inovação. A variável procura registrar esforços em inovação, além dos vinculados a $\mathrm{P} \& \mathrm{D}$, tais como os relativos a treinamento, implementação dos produtos, atividades internas de engenharia e

\footnotetext{
${ }^{8}$ Para uma explicação mais detalhada desse modelo, ver Greene (2010).
} 
aquisição externa de tecnologia. Admite-se que, quanto maior esse esforço, maior é a capacidade das firmas para absorver conhecimento.

- [cap_ext]: dummy que indica se a empresa apresenta participação de capital internacional. Considera-se que essa variável se associa à presença de empresas subsidiárias de multinacionais, vistas como líderes de CGV.

- [parte_grupo]: dummy que mede o efeito da empresa pertencer a um grupo empresarial.

- [prop_engenheiro]: proporção média (entre 2010 a 2012) de profissionais engenheiros e das áreas de ciências naturais e exatas no quadro total de empregados; o foco é a capacidade da empresa em absorver conhecimento.

\subsection{Resultados da exploração da base de dados}

A Tabela 1 mostra o número absoluto de firmas dos setores industriais da Argentina, bem como o percentual das que declararam exportar, merecendo realce a heterogeneidade quanto ao grau de internacionalização. Há dinamismo exportador nas indústrias farmacêutica, química e petroquímica e de maquinaria e equipamentos, além de setores tradicionais nas vendas externas argentinas, como alimentos. Associando o dinamismo exportador à participação em CGV, nota-se que tal inserção se dá preponderantemente em setores de alta tecnologia (AT) e média alta tecnologia (MAT), aparentemente confirmando o indicado por Corrêa et al (2017) sobre o segundo estágio das cadeias.

$\mathrm{Na}$ tabela 2 observa-se que quase $40 \%$ das firmas declararam ter atingido mercados internacionais. Dessas empresas, 37\% tiveram presença no conjunto Mercosul e América Latina, 8,6\% na América do Norte e Canadá, 10,5\% na Europa e 9,6\% no recorte Ásia, África e Oceania, observando-se, portanto, um forte caráter (macro)regional nessas vendas externas. Ao mesmo tempo, tais empresas também utilizam insumos oriundos de outras regiões mundiais, na proporção de $60 \%$ do conjunto estudado. A observação da distribuição espacial das origens dos provedores permite constatar uma maior diversificação, comparativamente aos destinos das exportações. Os provedores de Mercosul e América Latina representam 24,8\%, os de América do Norte e Canadá, $16,2 \%$, os da Europa, 22,7\%, e os de Ásia, África e Oceania, 23,1\%.

As variáveis relacionadas à inovação mostram que as firmas procuram inovar, tendo $2 / 3$ dos casos registrado algum tipo de inovação no período. Já o acesso a novos mercados, em decorrência do processo de inovação, caracteriza 26,7\% das empresas. Outro aspecto é que, na amostra de 3.691 empresas, 28,8\% possuíam vínculos com universidades e instituições públicas de C\&T, e 36,6\% com empresas de serviços de negócios intensivos em conhecimento (consultores). Cabe igualmente salientar que a maioria das empresas tem porte pequeno e médio, que apenas $9 \%$ contam com capital internacional e que $12,3 \%$ mantiveram interações com outras empresas do grupo ou com sua matriz para realizar inovações.

A tabela 3 informa que quase $40 \%$ das firmas não utilizaram fontes externas de conhecimentos no período. Trata-se, vale ressaltar, de uma proporção bastante elevada, no cotejo com resultados de pesquisas semelhantes: em Tether e Tajar (2008), por exemplo, o respectivo nível é de aproximadamente $3 \%$.

De outra parte, a proporção de funcionários relacionados às engenharias ou com formação nas áreas de ciências naturais e exatas apresenta uma média de $22 \%$ nos três anos observados (Tabela 4). A incidência é alta, se comparada ao resultado obtido por Tether e Tajar (2008), que detectaram uma proporção de $8 \%$ para ciências e engenharias e de $9 \%$ para outras formações universitárias.

As empresas pesquisadas gastaram com inovação uma cifra próxima a US\$ 413 mil por ano, em média (Tabela 5). Essa variável apresenta uma grande dispersão, refletindo a própria dispersão do tamanho das empresas argentinas, em linha com o resultado encontrado por Tether e Tajar (2008). No estudo desses autores, o valor médio do gasto com inovação foi de $£ 1.4$ milhão, enquanto que a mediana foi de $£ 38.500$. 
Tabela 1 - Distribuição das empresas argentinas por setor industrial - 2012

\begin{tabular}{|c|c|c|c|c|}
\hline Setor da indústria & $\begin{array}{c}\text { Firmas não } \\
\text { exportadoras }\end{array}$ & $\begin{array}{c}\text { Firmas } \\
\text { exportadoras }\end{array}$ & Total & $\begin{array}{c}\text { \% Firmas } \\
\text { exportadoras }\end{array}$ \\
\hline Máquinas-ferramentas em geral (MAT) & 39 & 85 & 124 & $69 \%$ \\
\hline Farmacêuticas (AT) & 51 & 85 & 136 & $63 \%$ \\
\hline Produtos químicos (MAT) & 69 & 112 & 181 & $62 \%$ \\
\hline Vinhos e outras bebidas fermentadas (BT) & 40 & 61 & 101 & $60 \%$ \\
\hline Outros & 37 & 49 & 86 & $57 \%$ \\
\hline Instrumentos médicos (AT) & 34 & 45 & 79 & $57 \%$ \\
\hline Maquinaria agropecuária e florestal (MAT) & 33 & 43 & 76 & $57 \%$ \\
\hline Máquinas e equipamentos (MAT) & 54 & 67 & 121 & $55 \%$ \\
\hline Produtos de borracha e plástico (MBT) & 97 & 95 & 192 & $49 \%$ \\
\hline Autopeças (MAT) & 70 & 64 & 134 & $48 \%$ \\
\hline Material elétrico, rádio, televisão (AT) & 77 & 58 & 135 & $43 \%$ \\
\hline Eletrodomésticos (MAT) & 49 & 32 & 81 & $40 \%$ \\
\hline Outros produtos de metal (MBT) & 142 & 86 & 228 & $38 \%$ \\
\hline Produtos têxteis (BT) & 126 & 72 & 198 & $36 \%$ \\
\hline Carrocerias, reboques e semi-reboques (MBT) & 24 & 13 & 37 & $35 \%$ \\
\hline Outros equipamentos de transporte (MAT) & 50 & 24 & 74 & $32 \%$ \\
\hline Metais comuns (MBT) & 88 & 41 & 129 & $32 \%$ \\
\hline Alimentos (BT) & 233 & 103 & 336 & $31 \%$ \\
\hline Frigoríficos (BT) & 124 & 51 & 175 & $29 \%$ \\
\hline Couro (BT) & 96 & 39 & 135 & $29 \%$ \\
\hline Edição (BT) & 98 & 38 & 136 & $28 \%$ \\
\hline Papel (BT) & 99 & 36 & 135 & $27 \%$ \\
\hline Móveis (BT) & 100 & 33 & 133 & $25 \%$ \\
\hline Outros minerais não metálicos (MBT) & 99 & 31 & 130 & $24 \%$ \\
\hline Produtos lácteos (BT) & 96 & 26 & 122 & $21 \%$ \\
\hline Confecções (BT) & 117 & 29 & 146 & $20 \%$ \\
\hline Madeira (BT) & 115 & 16 & 131 & $12 \%$ \\
\hline Total & 2.257 & 1.434 & 3.691 & $39 \%$ \\
\hline
\end{tabular}

Fonte: ENDEI (2015) 
Tabela 2 - Distribuição das variáveis dicotômicas

\begin{tabular}{|c|c|c|c|c|}
\hline Variável & Valor & Freq. & Percent. & Cum. \\
\hline \multirow{2}{*}{ exporta } & 0 & 2.257 & 61,2 & 61,2 \\
\hline & 1 & 1.434 & 38,9 & 100,0 \\
\hline \multirow{2}{*}{$A T$} & 0 & 3.341 & 90,5 & 90,5 \\
\hline & 1 & 350 & 9,5 & 100,0 \\
\hline \multirow{2}{*}{$M A T$} & 0 & 2.900 & 78,6 & 78,6 \\
\hline & 1 & 791 & 21,4 & 100,0 \\
\hline \multirow{2}{*}{$M B T$} & 0 & 2.975 & 80,6 & 80,6 \\
\hline & 1 & 716 & 19,4 & 100,0 \\
\hline \multirow{2}{*}{$B T$} & 0 & 1.943 & 52,6 & 44,8 \\
\hline & 1 & 1.748 & 47,6 & 100,0 \\
\hline \multirow{2}{*}{ importa } & 0 & 2.176 & 59,0 & 59,0 \\
\hline & 1 & 1.515 & 41,0 & 100,0 \\
\hline \multirow{2}{*}{ inova } & 0 & 1.256 & 34,0 & 34,0 \\
\hline & 1 & 2.435 & 66,0 & 100,0 \\
\hline \multirow{2}{*}{ result_merc } & 0 & 2.706 & 73,3 & 73,3 \\
\hline & 1 & 985 & 26,7 & 100,0 \\
\hline \multirow{2}{*}{ uni_inst } & 0 & 2.627 & 71,2 & 71,2 \\
\hline & 1 & 1.064 & 28,8 & 100,0 \\
\hline \multirow{2}{*}{ consultores } & 0 & 2.341 & 63,4 & 63,4 \\
\hline & 1 & 1.350 & 36,6 & 100,0 \\
\hline \multirow{2}{*}{ parte_grupo } & 0 & 3.236 & 87,7 & 87,7 \\
\hline & 1 & 455 & 12,3 & 100,0 \\
\hline \multirow{2}{*}{ cap_ext } & 0 & 3.354 & 90,9 & 90,9 \\
\hline & 1 & 337 & 9,1 & 100,0 \\
\hline \multirow{3}{*}{ tamanho } & peq & 1.569 & 42,5 & 42,5 \\
\hline & med & 1.352 & 36,6 & 79,1 \\
\hline & gra & 770 & 20,9 & 100,0 \\
\hline
\end{tabular}

Fonte: ENDEI (2015)

Tabela 3 - Utilização de fontes de informações externas

$N^{0}$ de fontes_ext

\begin{tabular}{ccrrr}
$\begin{array}{c}\text { No de fontes_ext } \\
\text { utilizadas por empresa }\end{array}$ & \multicolumn{1}{l}{ Freq. } & Percent. & Cum. \\
\hline 0 & 1460 & 39,6 & 39,6 \\
1 & 287 & 7,8 & 47,3 \\
2 & 327 & 8,9 & 56,2 \\
3 & 367 & 9,9 & 66,1 \\
4 & 367 & 9,9 & 76,1 \\
5 & 294 & 8,0 & 84,0 \\
6 & 249 & 6,8 & 90,8 \\
7 & 136 & 3,7 & 94,5 \\
& 105 & 2,8 & 97,3 \\
& 9 & 60 & 1,6 & 98,9 \\
& 10 & 39 & 1,1 & 100,0 \\
\hline Total & & $\mathbf{3 6 9 1}$ & $\mathbf{1 0 0 , 0}$ &
\end{tabular}


Tabela 4 - Proporção de engenheiros na força de trabalho

\begin{tabular}{cccccr}
\hline Variável & Obervações & $\begin{array}{c}\text { Média } \\
\text { (\%total) }\end{array}$ & $\begin{array}{c}\text { Desvio } \\
\text { Padrão }\end{array}$ & Min. & Max \\
\hline prop_eduin2010 & 3691 & 21,5 & 32,8 & 0 & 100 \\
prop_eduin2011 & 3691 & 21,7 & 32,6 & 0 & 100 \\
$\begin{array}{l}\text { prop_eduin2012 } \\
\text { prop_engenheiro } \\
\text { (2010-2012) }\end{array}$ & 3691 & 21,8 & 32,5 & 0 & 100 \\
\hline
\end{tabular}

Fonte: ENDEI (2015)

Tabela 5 - Gastos com inovação

\begin{tabular}{cccccc}
\hline Variável & Obervações & Média (US\$)* & $\begin{array}{c}\text { Desvio Padrão } \\
\text { (US\$) }\end{array}$ & $\begin{array}{c}\text { Min. } \\
\text { (US\$) }\end{array}$ & $\begin{array}{l}\text { Max. } \\
\text { (US\$) }\end{array}$ \\
\hline $\begin{array}{c}\text { inno_total2010 } \\
\text { inno_total2011 }\end{array}$ & 3691 & 337.526 & 2.338 .876 & 0 & 46.197 .675 \\
$\begin{array}{c}\text { inno_total2012 } \\
\text { gasto_innv }\end{array}$ & 3691 & 459.542 & 3.600 .886 & 0 & 72.504 .319 \\
$(2010-2012)$ & 3691 & 442.543 & 2.865 .393 & 0 & 60.393 .661 \\
\hline
\end{tabular}

Fonte: ENDEI (2015)

* Dados de câmbio em Ipeadata (IFS/FMI); Dados em Pesos correntes transformados em dólares pela taxa câmbio Peso/US\$, média do período; Peso/US\$(2010) = 3,8963, Peso/US\$(2011) = 4,1101, Peso/US\$(2012) = 4,5369

Por último, foram estimados cinco modelos Probit relacionando a inserção das empresas argentinas em CGV com as características chaves das empresas, conforme considerado na literatura. Os resultados da estimações encontram-se na tabela 6.

A abordagem das hipóteses de pesquisa apresentadas em 3.1 desenvolve-se como segue.

H1: A inserção de uma economia de média renda deverá se dar por meio das manufaturas de baixa intensidade tecnológica (BT), de média intensidade tecnológica (MBT/MAT), de alta intensidade tecnológica $(A T)$ e fornecimento de insumos.

Conforme a adaptação da "curva sorriso" proposta por Corrêa et al (2017), a inserção em CGV de uma economia de renda média como a Argentina se daria por meio das manufaturas de baixa intensidade tecnológica (BT), de média intensidade tecnológica (MBT/MAT), de alta intensidade tecnológica (AT) e de fornecimento de insumos. Pelas informações da tabela 1, com 27 setores relacionados, sete registram mais de 50\% das firmas com clientes no exterior. Destes, seis são manufatureiros MAT/AT.

$\mathrm{Na}$ modelagem econométrica contida na tabela 6, os coeficientes estimados indicam que pertencer a um setor de MAT aumenta a chance de inserção internacional da empresa por meio de exportações. Os coeficientes relacionados aos setores de AT não se mostraram significativos nos modelos relativos às exportações globais (exporta), para a América Latina (exp_al) e para a América do Norte (exp_an), ao contrário do verificado quando se tratou de Europa (exp_eu) e de Ásia, África e Oceania (exp_aao).

Para a América Latina, o coeficiente de BT foi negativo, sugerindo que pertencer a um setor de baixa tecnologia diminui a probabilidade de exportar para tal região. Mas esse resultado deve ser visto com cautela, pois, dada a alta concentração regional das exportações argentinas, pode haver 
algum tipo de competição entre as pautas de exportação dos setores de BT nos países do subcontinente. Resultado diverso é encontrado para os coeficientes dos setores de BT quando se trata de vendas para a América do Norte, para a Europa e para o conjunto de Ásia, África e Oceania: todos são positivos e significativos.

Acredita-se, assim, que o modo de participação das empresas argentinas em CGV é representativo do padrão exibido por países de renda média presentes no segundo estágio da "curva sorriso" adaptada por Corrêa et al (2017). A penetração desses países ocorre em cadeias de maior sofisticação tecnológica, mas em etapas caracterizadas por menor VA.

Tabela 6 - Resultados dos modelos econométricos

\begin{tabular}{|c|c|c|c|c|c|}
\hline Variável & $\begin{array}{l}\text { Modelo } 1 \\
\text { (exporta) }\end{array}$ & $\begin{array}{c}\text { Modelo } 2 \\
\text { (exp_al) }\end{array}$ & $\begin{array}{c}\text { Modelo 3 } \\
\text { (exp_an) }\end{array}$ & $\begin{array}{c}\text { Modelo } 4 \\
\text { (exp_eu) }\end{array}$ & $\begin{array}{l}\text { Modelo 5 } \\
\text { (exp_aao) }\end{array}$ \\
\hline AT & $\begin{array}{c}0.139 \\
(0.111)\end{array}$ & $\begin{array}{c}0.117 \\
(0.110)\end{array}$ & $\begin{array}{l}0.0618 \\
(0.153)\end{array}$ & $\begin{array}{c}0.312 * * \\
(0.138)\end{array}$ & $\begin{array}{c}0.659 * * * \\
(0.142)\end{array}$ \\
\hline MAT & $\begin{array}{c}0.295 * * * \\
(0.0876) \\
\end{array}$ & $\begin{array}{c}0.308 * * * \\
(0.0874) \\
\end{array}$ & $\begin{array}{c}0.297 * * \\
(0.118) \\
\end{array}$ & $\begin{array}{c}0.243 * * \\
(0.112) \\
\end{array}$ & $\begin{array}{c}0.345^{* * *} \\
(0.123) \\
\end{array}$ \\
\hline BT & $\begin{array}{c}-0.121 \\
(0.0748)\end{array}$ & $\begin{array}{c}-0.176 * * \\
(0.0751)\end{array}$ & $\begin{array}{c}0.532 * * * \\
(0.109)\end{array}$ & $\begin{array}{c}0.420 * * * \\
(0.103)\end{array}$ & $\begin{array}{c}0.565^{* * *} \\
(0.114)\end{array}$ \\
\hline imp_al & $\begin{array}{c}0.437 * * * \\
(0.0729)\end{array}$ & $\begin{array}{c}0.461 * * * \\
(0.0725)\end{array}$ & $\begin{array}{c}0.250 * * * \\
(0.0921)\end{array}$ & $\begin{array}{l}0.183 * * \\
(0.0874)\end{array}$ & $\begin{array}{l}0.222 * * \\
(0.0890)\end{array}$ \\
\hline imp_an & $\begin{array}{l}0.182 * * \\
(0.0899) \\
\end{array}$ & $\begin{array}{l}0.186 * * \\
(0.0891) \\
\end{array}$ & $\begin{array}{l}0.248 * * \\
(0.0972) \\
\end{array}$ & $\begin{array}{c}0.278 * * * \\
(0.0950)\end{array}$ & $\begin{array}{c}0.184 * \\
(0.0970) \\
\end{array}$ \\
\hline imp_eu & $\begin{array}{c}0.440 * * * \\
(0.0766) \\
\end{array}$ & $\begin{array}{c}0.372 * * * \\
(0.0762) \\
\end{array}$ & $\begin{array}{c}0.499 * * * \\
(0.0924) \\
\end{array}$ & $\begin{array}{c}0.463 * * * \\
(0.0895) \\
\end{array}$ & $\begin{array}{c}0.452 * * * \\
(0.0908) \\
\end{array}$ \\
\hline imp_aao & $\begin{array}{c}0.299 * * * \\
(0.0740)\end{array}$ & $\begin{array}{c}0.307 * * * \\
(0.0738)\end{array}$ & $\begin{array}{l}-0.0677 \\
(0.0951)\end{array}$ & $\begin{array}{l}-0.0650 \\
(0.0894)\end{array}$ & $\begin{array}{c}-0.132 \\
(0.0893)\end{array}$ \\
\hline o.inova & - & - & - & - & - \\
\hline result_merc & $\begin{array}{c}0.242 * * * \\
(0.0589) \\
\end{array}$ & $\begin{array}{c}0.240 * * * \\
(0.0591)\end{array}$ & $\begin{array}{l}0.157 * * \\
(0.0769) \\
\end{array}$ & $\begin{array}{c}0.272 * * * \\
(0.0722)\end{array}$ & $\begin{array}{c}0.257 * * * \\
(0.0748)\end{array}$ \\
\hline uni_inst & $\begin{array}{c}0.266 * * * \\
(0.0667) \\
\end{array}$ & $\begin{array}{c}0.273 * * * \\
(0.0668) \\
\end{array}$ & $\begin{array}{c}0.143 * \\
(0.0867) \\
\end{array}$ & $\begin{array}{l}0.185 * * \\
(0.0817) \\
\end{array}$ & $\begin{array}{l}0.196 * * \\
(0.0822) \\
\end{array}$ \\
\hline consultores & $\begin{array}{c}0.0251 \\
(0.0627)\end{array}$ & $\begin{array}{c}0.0270 \\
(0.0631) \\
\end{array}$ & $\begin{array}{c}0.0572 \\
(0.0823)\end{array}$ & $\begin{array}{l}-0.0164 \\
(0.0775)\end{array}$ & $\begin{array}{c}0.0256 \\
(0.0789)\end{array}$ \\
\hline fontes_ext & $\begin{array}{c}0.0298 * * \\
(0.0133)\end{array}$ & $\begin{array}{c}0.0374 * * * \\
(0.0134)\end{array}$ & $\begin{array}{l}0.00725 \\
(0.0168)\end{array}$ & $\begin{array}{c}0.0243 \\
(0.0163)\end{array}$ & $\begin{array}{c}0.0195 \\
(0.0172)\end{array}$ \\
\hline ln_inv & $\begin{array}{c}0.0133 \\
(0.0195) \\
\end{array}$ & $\begin{array}{l}0.00272 \\
(0.0195) \\
\end{array}$ & $\begin{array}{c}0.0239 \\
(0.0250) \\
\end{array}$ & $\begin{array}{l}-0.0120 \\
(0.0235) \\
\end{array}$ & $\begin{array}{c}0.0552 * * \\
(0.0256) \\
\end{array}$ \\
\hline cap_ext & $\begin{array}{l}0.190 * \\
(0.107) \\
\end{array}$ & $\begin{array}{l}0.184 * \\
(0.106) \\
\end{array}$ & $\begin{array}{c}0.306^{* * * *} \\
(0.109)\end{array}$ & $\begin{array}{c}0.389 * * * \\
(0.105)\end{array}$ & $\begin{array}{l}0.0807 \\
(0.110) \\
\end{array}$ \\
\hline tam_peq & $\begin{array}{c}-0.283 * * * \\
(0.0678)\end{array}$ & $\begin{array}{c}-0.308 * * * \\
(0.0685)\end{array}$ & $\begin{array}{l}-0.0161 \\
(0.0994)\end{array}$ & $\begin{array}{l}-0.168 * \\
(0.0923) \\
\end{array}$ & $\begin{array}{c}-0.244 * * \\
(0.101)\end{array}$ \\
\hline tam_gra & $\begin{array}{l}0.183 * * \\
(0.0834)\end{array}$ & $\begin{array}{l}0.177 * * \\
(0.0833)\end{array}$ & $\begin{array}{c}0.148 \\
(0.102)\end{array}$ & $\begin{array}{l}0.248 * * \\
(0.0963)\end{array}$ & $\begin{array}{c}0.301 * * * \\
(0.0988)\end{array}$ \\
\hline prop_engenheiro & $\begin{array}{c}0.00256 * * * \\
(0.000932)\end{array}$ & $\begin{array}{c}0.00301 * * * \\
(0.000930)\end{array}$ & $\begin{array}{c}0.00331 * * * \\
(0.00115)\end{array}$ & $\begin{array}{l}0.000979 \\
(0.00112) \\
\end{array}$ & $\begin{array}{l}0.00196 * \\
(0.00117) \\
\end{array}$ \\
\hline Constant & $\begin{array}{c}-0.958 * * * \\
(0.246)\end{array}$ & $\begin{array}{c}-0.896 * * * \\
(0.245)\end{array}$ & $\begin{array}{c}-2.573 * * * \\
(0.333)\end{array}$ & $\begin{array}{c}-1.933 * * * \\
(0.307)\end{array}$ & $\begin{array}{c}-2.958 * * * \\
(0.342)\end{array}$ \\
\hline Pseudo R2 & 0.2051 & 0.2109 & 0.1521 & 0.1474 & 0.1788 \\
\hline
\end{tabular}




\begin{tabular}{lccccc} 
Wald Chi2 & 513.51 & 535.24 & 241.21 & 274.62 & 278.14 \\
AIC & 2.634 .703 & 2.608 .448 & 1.541 .572 & 1.656 .569 & 1513.66 \\
\hline Observations & 2,361 & 2,361 & 2,361 & 2,361 & 2,361 \\
\hline Robust standard errors in parentheses & & & \\
$* * * \mathrm{p}<0.01, * * \mathrm{p}<0.05, * \mathrm{p}<0.1$ & \multicolumn{5}{c}{ Fonte: Elaboração própria com base em ENDEI (2015) }
\end{tabular}

H2: A inserção de uma economia de média renda acontece em etapas intensivas em mão de obra, processamento e montagem, sem a presença de processo de endogeneização tecnológica $e$, portanto, sendo forte a preponderância dos provedores externos, o que repercute em perda de valor adicionado (VA) para a economia do país.

Se a América Latina prepondera como destino na participação das empresas argentinas em CGV pelo ângulo das exportações, o mesmo não se pode falar com respeito à inserção por meio das importações. Nestas, a distribuição geográfica das origens dos fluxos mostra-se mais equilibrada.

Um aspecto a destacar também é que a observação dos coeficientes das importações conforme as origens indica que empresas que importam têm aumentada a probabilidade de exportar para todas as outras regiões. Isso deve ser associado ao prevalecente caráter de montagem e processamento das atividades protagonizadas pelas empresas argentinas, sob o signo de uma pequena endogeneização tecnológica.

H3: Empresas com maior capacidade de absorção (CA) de informações conseguem explorar o conhecimento externo de forma mais eficiente, aumentando o seu desempenho inovativo e sua inserção em $C G V$.

A tabela 2 informou que $66 \%$ das firmas declararam inovar e que aproximadamente $27 \%$ tiveram alguma inovação capaz de resultar em presença em algum novo mercado. Contudo, pela tabela 3 observa-se que quase $40 \%$ não buscaram sequer uma única fonte externa de conhecimento especializado, um tipo de assunto explorado na abordagem de Chesbrough (2003) em termos de "inovação aberta", como tangenciado anteriormente no artigo.

A tabela 6 mostra que a variável inova foi omitida por colinearidade. Os coeficientes da variável prop_engenheiro, que considera a parcela de profissionais engenheiros e com formação em ciências naturais e exatas - representando uma proxy para $\mathrm{CA}-$, foram positivos e significativos para todos os modelos, excetuado o relativo à Europa (expo_eu). Depreende-se, assim, que tal variável indica que, de fato, uma maior CA vai de par com uma maior inserção em CGV.

Por outro lado, o gasto com inovação não se mostrou significativo. Mas tal resultado mereceria um estudo cuidadoso, para verificar se as empresas investem mesmo em inovação.

H4: A colaboração indústria-universidade é voltada ao desenvolvimento de inovações com elevado grau de complexidade, incluindo novos produtos e favorecendo uma participação em CGV escorada em maior desenvolvimento e complexidade em produtos e processos.

Os coeficientes da regressão parecem condizentes com esta hipótese. Em todos os casos, ter vínculo com universidade ou instituição de C\&T aumenta a probabilidade da firma exportar e inserir-se em CGV. De outra parte, os coeficientes relacionados ao uso de consultores privados não representaram ampliação da probabilidade de aumento da inserção das firmas em CGV.

\section{Considerações finais}

O aumento da presença de CGV, como configurações destacadas na produção e no comércio internacional nas últimas décadas, tornou a participação dos diferentes tipos de países nessas estruturas um importante tema de investigação acadêmica, além de motivação para formular e executar políticas. Geralmente, países de renda média têm lugar nessas cadeias, segundo a literatura, como fabricantes e exportadores de produtos em que se observam distintas intensidades 
tecnológicas, porém relacionados a etapas produtivas em que é comparativamente maior a intensidade no uso de mão de obra e a incidência de processamento e montagem final, com fraca endogeneização tecnológica.

Esse modo de envolvimento, contudo, pode acenar com possibilidade de transição para etapas representativas de maior valor agregado (VA), em upgrading no âmbito das CGV que, de uma forma geral, costuma ter na dinâmica de inovação um vetor de grande relevância. Assim, principalmente no que concerne aos países de renda média, têm destaque no debate sobre CGV assuntos relacionados ao upgrading industrial e, por extensão, às condições que subjazem à sua possibilidade e ocorrência.

$\mathrm{O}$ artigo debruçou-se sobre esse tipo de problema, de uma maneira exploratória, lançando um olhar na situação de quase 3.700 empresas industriais argentinas, de diferentes setores e tamanhos, conforme possibilitado por uma base de dados construída em escala ministerial naquele país, cobrindo os anos de 2010 a 1012. O manuseio desses dados, que incluiu sobretudo a estimação de modelos Probit, sugeriu que se confirmam na Argentina as postulações trazidas na literatura sobre o perfil do envolvimento de economias de renda média nas amplas estruturas produtivas e comerciais correspondentes às CGV.

Entre as firmas argentinas incluídas na referida base de dados, notou-se algum dinamismo exportador em setores de alta e média/alta tecnologia, mas parece prevalecer, nas atividades protagonizadas, o caráter de montagem e processamento, com endogeneização tecnológica limitada. Essas vendas, como assinalado no texto, apresentam elevada concentração em mercados da América Latina. De outra parte, um considerável número de empresas declarou realizar inovações, com resultados comerciais importantes. Todavia, muitas não mobilizavam fontes externas de obtenção de informações e conhecimento, uma questão central na problemática da chamada "inovação aberta", como se falou. De todo modo, é comparativamente elevada a proporção de engenheiros e de outros profissionais com formação em ciências naturais e exatas no corpo de assalariados das firmas, o que pode ser considerado promissor com vistas ao upgrading.

Nesse contexto, uma questão central - para firmas argentinas e de outros países de renda média que registram envolvimento em CGV - diz certamente respeito, entre outros aspectos, a como intensificar e acelerar o processo de endogeneização tecnológica, para evitar o aprisionamento na armadilha da renda média, conforme abordado no corpo do artigo. Tal processo haveria de representar possibilidades concretas de avanços decisivos em upgrading, isto é, chances de migração para etapas, na participação em CGV, associadas a patamares mais altos de VA.

O terreno a laborar, nesta e em outras experiência semelhantes, não é outro senão, com maior destaque, o das políticas de apoio e fomento. Mas tais políticas teriam que ser de fato concebidas tendo-se em vista a problemática específica da participação em CGV. Em que medida a Argentina, e, entre outros países, também o Brasil, estariam de fato procurando idealizar instrumentos de ação com tal perfil, que em vários sentidos parece exigir diferenciação do se fez tradicionalmente nessas economias?

\section{Referências}

ASHEIM, B.; GERTLER, M., The geography of innovation. In: FAGERBER, J.; MOWERY, D.; NELSON, R. (Eds.) The Oxford Handbook of Innovation. Oxford: Oxford University Press, 2005.

BALDWIN, R. Trade and industrialisation after globalisation's 2nd unbundling: how building and joining a supply chain are different and why it matters. NBER Working Paper No. 17716, Dec., 2011.

BALDWIN, R Global supply chains: why they emerged, why they matter, and where they are going. Fung Global Institute, Working Paper 2012-01, 2012. 
BELDERBOS, R.; CARREE, M.; DIEDEREN, B.; LOKSHIN, B.; VEUGELERS, R. Heterogeneity in R\&D co-operation strategies. International Journal of Industrial Organization, v. 22, p. 1237-63, 2004.

BHAGWATI, J. N; DEHEJIA, V. Freer Trade and Wages of the Unskilled: Is Marx Striking Again? In: BHAGWATI, J. N.; KOSTERS, M. H., (Eds.). Trade and Wages: Leveling Wages Down? Washington, D.C.: The American Enterprise Institute Press, 1994, p. 36-75.

BSTIELER, L.; HEMMERT, M.; BARCZAK, G. Trust formation in university-industry collaborations in the US biotechnology industry: IP policies, shared governance, and champions. Journal of Product Innovation Management, v. 32, n. 1, p. 111-21, 2015.

CARLSSON, B. (Ed.). Technological systems and industrial dynamics. Boston/Dordrecht/London: Kluwer Academic Publishers, 1997.

CHESBROUGH, H. W. Open innovation: the new imperative for creating and profiting from technology[M]. Boston: Harvard Business School Press, 2003.

COHEN, W. M.; LEVINTHAL, D. A. Absorptive capacity: a new perspective on learning and innovation. Administrative Science Quarterly, v. 35, p. 128-152, 1990.

COOMBS, R.; HARVEY,M.; TETHER, B.S. Analysing distributed processes of provision and innovation. Industrial and Corporate Change, v. 12, n. 6, p. 1125-1155, 2003.

CORREAA, L. M.; PINTO, E. C.; CASTILHO, M. Trajetórias dos países nas cadeias globais de valor: padrões de atuação, estágios produtivos e mudança estrutural. Texto para Discussão, n. 7, IEUFRJ, 2017.

EBERS, M.; MAURER, I. Connections count: how relational embeddedness and relational empowerment foster absorptive capacity. Research Policy, v. 43, p. 318 -332, 2014.

EDQUIST, C. (Ed.). Systems of innovation: technologies, institutions and organizations. London: Pinter, 1997.

EDQUIST, C., Systems of innovation: perspectives and challenges. In: FAGERBERG, J.; MOWERY, D.; NELSON, R. (Eds.). The Oxford Handbook of Innovation. Oxford: Oxford University Press, 2005.

EICHENGREEN, B. Escaping the middle income trap. ECONOMIC POLICY SYMPOSIUM 2011, Federal Reserve Bank of Kansas City, 2011.

ESCRIBANO, A.; FOSFURI, A.; TRIBÓ, J.A. Managing external knowledge flows: the moderating role of absorptive capacity. Research Policy, v. 38, p. 96-105, 2009.

GEREFFI, G. The organization of buyer-driven global commodity chains: how U.S. retailers shape overseas production networks. In: GEREFFI, G.; KORZENIEWICZ, M. (Eds.). Commodity chains and global capitalism. London: Greenwood Press, 1994, p. 95-122.

GEREFFI, G. Shifting governance structures in global commodity chains, with special reference to the internet. American Behavioral Scientist, v. 44, n. 10, p. 1616-1637, 2001.

GEREFFI, G.; HUMPHREY, J.; STURGEON, T. The governance of global value chains. Review of International Political Economy, v. 12, n. 1, p. 78-104, 2005.

GEREFFI, G.; STURGEON, T. Global value chains and industrial policy: the role of emerging economies. In: ELMES, D.; LOW, P. (Eds.). Global value chains in a changing world. Geneva: WTO, 2013.

GREENE, W. H.; HENSHER, D. A. Modeling ordered choices: a primer. Cambridge, MA: Cambridge University Press, 2010. 
HAUSMANN, R.; HIDALGO, C. A.; BUSTOS, S.; COSCIA, M.; CHUNG, S.; JÍMENEZ, J.; SIMÕES, A.; YILDIRIM, M. A. The Atlas of Economic Complexity: Mapping Paths to Prosperity. Cambridge, MA, 2011.

HSIEH,W. L., GANOTAKIS, P.; KAFOUROS, M.; Wang C. Foreign and domestic collaboration, product innovation novelty, and firm growth. J Prod. Innov. Manag, DOI: 10.1111/jpim.12435, 2017.

HUMPHREY, J.; SCHMITZ, H. How does insertion in global value chains affect upgrading in industrial clusters? Regional Studies, v. 36, p. 1017-27, 2002.

INCE, H.; IMAMOGLU. S. Z.; TURKCANA, H. The effect of technological innovation capabilities and absorptive capacity on firm innovativeness: a conceptual framework. Social and Behavioral Sciences, v. 235, p. 764-770, 2016.

JENSEN, M. B.; JOHNSON, B.; LORENZ, E.; LUNDVALL, B. A. Forms of knowledge and modes of innovation. Research Policy, , v. 36, n. 5, p. 680-693, 2007.

KLEVORICK, A.; LEVIN, R.; NELSON, R.; WINTER, S. On the sources and significance of interindustry differences in technological opportunities. Research Policy, v. 24, n. 2, p.185-205, 1995.

LAMY, P. Global value chains, interdependence, and the future of trade. VOX CEPR's Political Portal, 18 dez. 2013. Obtido em: https://voxeu.org/article/global-value-chains-interdependence-andfuture-trade Acesso em: 20/04/2018.

LAURSEN, K; SALTER, A. J. The paradox of openness: appropriability, external search and collaboration. Research Policy, v. 43, n. 5, p. 867-878, 2014.

LUNDVALL, B.-A. (Ed.). National systems of innovation: towards the theory of innovation and interactive learning. London: Pinter Publishers, 1992.

MALERBA, F. (Ed.). Sectoral Systems of Innovation - concepts, issues and analyses of six major sectors in Europe. Cambridge University Press, Cambridge, 2004.

MALERBA, F. Sectoral systems: how and why innovation differs across sectors. In: FAGERBER, J.; MOWERY, D.; NELSON, R. (Eds.). The Oxford Handbook of Innovation. Oxford: Oxford University Press, 2005.

MEMEDOVIC, O.; IAPADRE, L. Structural change in the world economy: main features and change. UNIDO, Research and Statistics Branch, Working Paper n. 24/2009, 2009.

MENTION, A. L. Co-operation and co-opetition as open innovation practices in the service sector: which influence on innovation novelty? Technovation, v. 31, n. 1, p. 44-53, 2011.

MILBERG, W.; WINKLER, D. Outsourcing economics: global value chains in capitalist development . Cambridge: Cambridge University Press, 2013.

MUROVEC, N.; PRODAN, I. Absorptive capacity, its determinants, and influence on innovation output: cross-cultural validation of the structural model. Technovation, v. 29, n. 12, p. $859-872$, 2009.

NELSON, R. R. National innovation systems: the comparative analysis. New York: Oxford University Press, 1993.

NEVES, L.P. A inserção do Brasil nas cadeias globais de valor. CEBRI Dossiê Edição Especial, v. 2, ano 13. Rio de Janeiro: CEBRI, 2014.

PIETROBELLI, C.; RABELLOTTI, R. Clusters and value chains in Latin America: in search of an integrated approach. In: PIETROBELLI, C.; RABELLOTTI, R. (Eds.). Global value chains, clusters and SMEs in Latin America. Washington: IDB, 2006. 
PINTO, E.; FIANI, C.; CORRÊA, L.M. Dimensões da abordagem da cadeia global de valor: upgrading, governança, políticas governamentais e propriedade intelectual. In: OLIVEIRA, I. T.; CARNEIRO, F. L.; SILVA FILHO, E. B. da (Orgs.). Cadeias globais de valor, políticas públicas e desenvolvimento. Brasília : Ipea, 2017.

POWELL,W.; GRODAL, S. Networks of innovators. In: FAGERBERG, J.; MOWERY, D.; NELSON, R. (Eds.) The Oxford Handbook of Innovation. Oxford University Press, Oxford, 2005.

RICARDO, D. Princípios de economia política e tributação. São Paulo: Nova Cultural, 1996.

TETHER, B.S.; METCALFE, J.S. Services and systems of innovation. In: MALERBA, F. (Ed.). Sectoral systems of innovation - concepts, issues and analyses of six major sectors in Europe. Cambridge: Cambridge University Press, 2004.

TETHER, B. S.; TAJAR, A. Beyond industry-university links: sourcing knowledge for innovation from consultants, private research organizations and the public science-base. Research Policy, v. 37, n. 6, p. 1079-1095, 2008.

TIMMER, M. P.; LOS, B.; STEHRER, R.; de VRIES, G. J. Fragmentation, incomes and jobs: an analysis of European competitiveness. Economic Policy, v. 28, p. 613-661, 2013.

UN, C. A.; ASAKAWA, K. Types of R\&D collaborations and process innovation: the benefit of collaborating upstream in the knowledge chain. Journal of Product Innovation Management, v. 32, n. 1, p. 138-53, 2015.

UNCTAD-WIR13. World Investment Report 2013. New York and Geneva: United Nations, 2013.

UNIDO. Industrial Development Report 2013. Viena: United Nations Industrial Development Organization, 2013.

VERDOORN, P. J. Verdoorn's law in retrospect: a comment. The Economic Journal, v. 90, n. 358, p. 382-385, 1980.

VIOTTI, E. B.; MACEDO, M. M. (Orgs.). Indicadores de ciência, tecnologia e inovação no Brasil. Campinas: Ed. Da UNICAMP, 2003.

WIRSICH, A.; KOCK, A.; STRUMANN, C; SCHULTZ, C. Effects of university-industry collaboration on technological newness of firms. Journal of Product Innovation Management, v. 33, n. 6, p. 708-25, 2016. 